\title{
Case Report \\ Choroidal Coloboma in a Case of Tay-Sachs Disease
}

\author{
Nasreen Raees Ahmed, Koushik Tripathy, Vivek Kumar, and Varun Gogia \\ Department of Ophthalmology, Dr. R. P. Centre, All India Institute of Medical Sciences, New Delhi 110029, India \\ Correspondence should be addressed to Nasreen Raees Ahmed; nasreenraees1@gmail.com
}

Received 23 June 2014; Revised 19 August 2014; Accepted 24 August 2014; Published 10 September 2014

Academic Editor: Antonio Ferreras

Copyright (c) 2014 Nasreen Raees Ahmed et al. This is an open access article distributed under the Creative Commons Attribution License, which permits unrestricted use, distribution, and reproduction in any medium, provided the original work is properly cited.

Coloboma as an ocular finding has been documented in various syndromes. Here we have a case of infantile Tay-Sachs disease associated with unilateral choroidal coloboma. To the best of our knowledge, such an association has not been documented in the literature. Whether such an association is a matter of chance or signifies the involvement of ganglioside metabolism in ocular embryogenesis remains to be elucidated.

\section{Introduction}

Coloboma occurs due to failure of closure of the choroidal fissure during 5 to 7 weeks of embryonic development. It may occur as an isolated finding or have a syndromic association. Its association with various syndromes has given further insight into the pathogenesis. The association of coloboma with lysosomal storage disorders such as Tay-Sachs disease has never been documented before. Whether such an association is a matter of chance or signifies the involvement of ganglioside metabolism in ocular embryogenesis remains to be elucidated.

\section{Case Report}

A 2-year-old male child was referred from paediatrics for visual function evaluation. The child was brought by his parents with complaints that the child does not reach for objects, is unable to sit with or without support, and has generally become less playful than before.

The developmental history was suggestive of global neurological regression. On examination he was found to have generalized hypotonia with hyperreflexia. No organomegaly was present. Patient had an excessive startle response.

The parents gave history of second degree of consanguineous marriage. A detailed family history was taken (Figure 1). Patient had three older male siblings. The siblings were thoroughly evaluated and found to have normal neurological development as per age. There was no history of demise of any family member at a young age.
On ocular examination, pupils were reactive to light. The child did not fixate or follow light. The anterior segment in the right eye was within normal limits. In the left eye a typical iris coloboma was appreciated in the inferonasal quadrant (Figure 2). The lens in both eyes was transparent. A cherry red spot was noted in both eyes. Rest of the fundus was normal in the right eye (Figure 3). Left eye showed type III choroidal coloboma by Ida Mann's classification (Figure 4). No disc pallor was noted.

There was no evidence of nystagmus or strabismus. Refraction under cyclopentolate $0.5 \%$ was performed. Right eye had a spherical equivalent of $+1.5 \mathrm{D}$ and left eye had a spherical equivalent of $+2.00 \mathrm{D}$. Visually evoked potential by flash stimuli showed an extinguished response in both eyes.

Blood sample sent for enzyme analysis revealed deficiency of hexosaminidase A enzyme (5.89 nmol/hr/mg). MRI scan of the brain revealed areas of hyperintensity in the supratentorial white matter, bilateral corpus striatum, and external capsule with mild cerebral atrophy. The findings were compatible with GM2 gangliosidosis-Tay-Sachs disease.

\section{Discussion}

Coloboma can occur as an isolated finding or in association with systemic features. The literature is replete with systemic associations of coloboma. While some of these associations are consistent with known genetic loci, others are of unknown etiology. Syndromes known to be autosomally dominant 


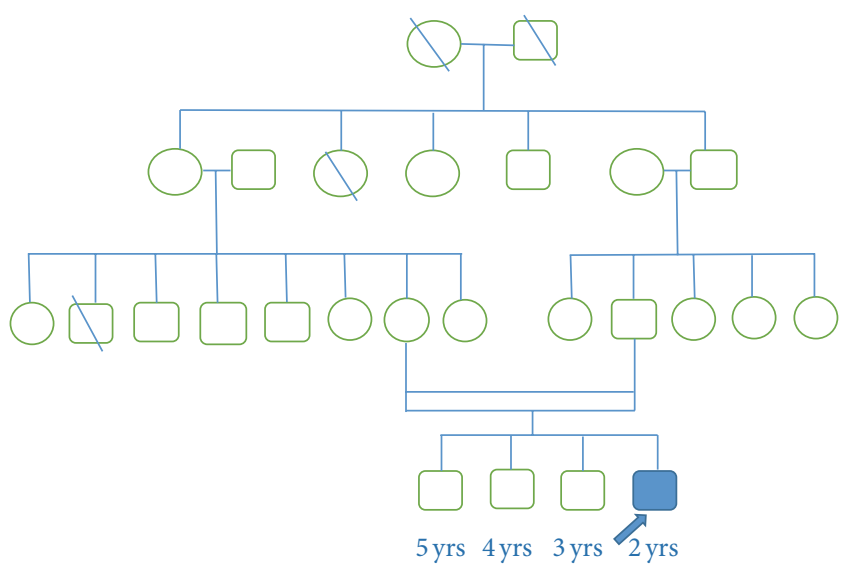

FIGURE 1

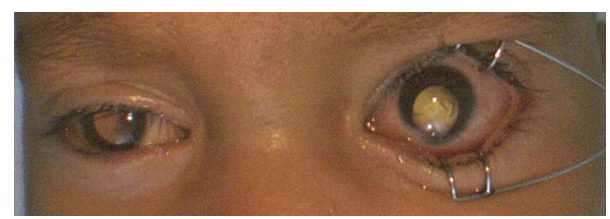

FIGURE 2

in inheritance include Gorlin Goltz or nevoid basal cell carcinoma syndrome [1], renal coloboma syndrome [2], Noonan's syndrome [3], Rubinstein-Taybi syndrome [4], and Crouzon syndrome [5]. Syndromes with autosomal recessive inheritance pattern include Walker-Warburg syndrome [6], Joubert syndrome [7], Bardet Biedl syndrome [8], Ellis van Creveld syndrome [9], Kartagener syndrome [10], and Meckel-Gruber syndrome [11]. X-linked recessive inheritance is seen in Lenz syndrome [12] while X-linked dominant inheritance is seen in Aicardi syndrome [13], focal dermal hypoplasia [14], and orofaciodigital syndrome [15]. Chromosomal aberrations are also associated with coloboma [16].

Ours is a case of coloboma in Tay-Sachs disease wherein there is abnormal accumulation of GM2 gangliosides in cells due to lack of a lysosomal enzyme, hexosaminidase A. This could suggest a role of gangliosides and their lysosomal metabolism in ocular morphogenesis. In a study by Blackburn et al., embryonic chick neural retina cells were incubated on surfaces adsorbed with gangliosides and a surface adsorbed with neutral glycosphingolipids, phospholipids, and sulfatide [17]. Rapid and specific cell adhesion was detected on the former. The cell adhesion varied with different purified gangliosides; GM2, GD3, and GD1 showed highest adhesion while GM1, GD1b, and GT1b showed less adhesion. This suggests a role of gangliosides in cell-cell recognition in the developing neural retinal tissue. In a study done by Dreyfus et al., there was a change in pattern of ganglioside expression with age in the retina of chick embryo [18]. Therefore any perturbation in the amount and type of ganglioside expression during embryogenesis would have profound effects on neural and retinal tissue development and differentiation. Further studies are required to identify the role played by gangliosides in ocular development.

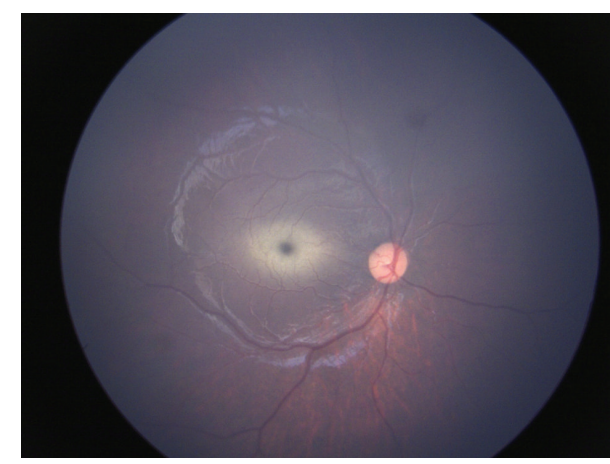

FIGURE 3

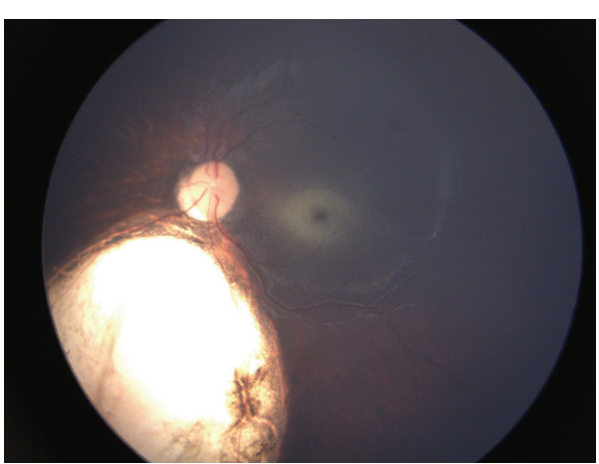

Figure 4

However there is a strong possibility of occurrence of coloboma in our case to be a coincidental finding as no such association has been documented previously.

\section{Conclusion}

Research done on pathogenesis of coloboma has brought into light the genes and signalling pathways involved in ocular morphogenesis. Reporting various associations found with coloboma has not only helped to identify novel signalling pathways but also helped spearhead research into specific areas of a very complex and interconnected process of embryogenesis. The association of a lysosomal storage disorder with coloboma may be a coincidental finding in our case. Documentation of more such cases can suggest the involvement of gangliosides in ocular morphogenesis; however further research is required to expand our knowledge on the role played by gangliosides, if any, in ocular morphogenesis.

\section{Conflict of Interests}

The authors declare that there is no conflict of interests regarding the publication of this paper. 


\section{References}

[1] G. Manzi, A. Magli, B. Pignalosa, and G. Liguori, "The GorlinGoltz syndrome: case report,” Ophthalmologica, vol. 200, no. 2, pp. 104-106, 1990.

[2] P. Dureau, T. Attie-Bitach, R. Salomon et al., "Renal coloboma syndrome," Ophthalmology, vol. 108, no. 10, pp. 1912-1916, 2001.

[3] F. J. Ascaso, M. A. del Buey, V. Huerva, B. Latre, and A. Palomar, "Noonan's syndrome with keratoconus and optic disc coloboma," European Journal of Ophthalmology, vol. 3, no. 2, pp. 101-103, 1993.

[4] F. H. Roy, R. L. Summitt, R. L. Hiatt, and J. G. Hughes, "Ocular manifestations of the Rubinstein-Taybi syndrome: case report and review of the literature," Archives of Ophthalmology, vol. 79, no. 3, pp. 272-278, 1968.

[5] S. Kreiborg and M. M. Cohen Jr., "Ocular manifestations of Apert and Crouzon syndromes: qualitative and quantitative findings," Journal of Craniofacial Surgery, vol. 21, no. 5, pp. 13541357, 2010.

[6] W. B. Dobyns, R. A. Pagon, D. Armstrong et al., "Diagnostic criteria for Walker-Warburg syndrome," American Journal of Medical Genetics, vol. 32, no. 2, pp. 195-210, 1989.

[7] D. Lindhout, P. G. Barth, J. Valk, and T. N. Boen-Tan, "The Joubert Syndrome associated with bilateral chorioretinal coloboma," European Journal of Pediatrics, vol. 134, no. 2, pp. 173-176, 1980.

[8] A. P. Schachat and I. H. Maumenee, "Bardet-Biedl syndrome and related disorders," Archives of Ophthalmology, vol. 100, no. 2, pp. 285-288, 1982.

[9] F. E. Tubbs, L. Crevasse, and J. R. Green Jr., "Congenital heart disease in an adult with the Ellis-van Creveld syndrome," Annals of Internal Medicine, vol. 57, no. 5, pp. 829-834, 1962.

[10] H. D. Rott, "Kartagener's syndrome and the syndrome of immotile cilia," Human Genetics, vol. 46, no. 3, pp. 249-261, 1979.

[11] C. P. Chen, "Meckel syndrome: genetics, perinatal findings, and differential diagnosis," Taiwanese Journal of Obstetrics \& Gynecology, vol. 46, no. 1, pp. 9-14, 2007.

[12] E. Hilton, J. Johnston, S. Whalen et al., "BCOR analysis in patients with OFCD and Lenz microphthalmia syndromes, mental retardation with ocular anomalies, and cardiac laterality defects," European Journal of Human Genetics, vol. 17, no. 10, pp. 1325-1335, 2009.

[13] J. Aicardi, "Aicardi syndrome," Brain \& Development, vol. 27, no. 3, pp. 164-171, 2005.

[14] R. W. Goltz, "Focal dermal hypoplasia syndrome: an update," Archives of Dermatology, vol. 128, no. 8, pp. 1108-1111, 1992.

[15] G. Annerén, B. Arvidson, K. H. Gustavson, H. Jorulf, and G. Carlsson, "Oro-facio-digital syndromes I and II: radiological methods for diagnosis and the clinical variations," Clinical Genetics, vol. 26, no. 3, pp. 178-186, 1984.

[16] C. Y. Gregory-Evans, M. J. Williams, S. Halford, and K. GregoryEvans, "Ocular coloboma: A reassessment in the age of molecular neuroscience," Journal of Medical Genetics, vol. 41, no. 12, pp. 881-891, 2004.

[17] C. C. Blackburn, P. Swank-Hill, and R. L. Schnaar, "Gangliosides support neural retina cell adhesion," The Journal of Biological Chemistry, vol. 261, no. 6, pp. 2873-2881, 1986.

[18] H. Dreyfus, P. F. Urban, S. Edel Harth, and P. Mandel, "Developmental patterns of gangliosides and of phospholipids in chick retina and brain," Journal of Neurochemistry, vol. 25, no. 3, pp. 245-250, 1975. 


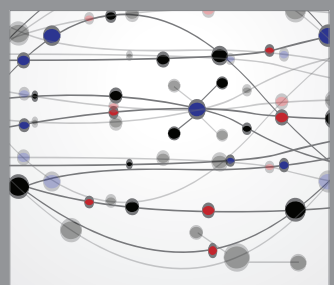

The Scientific World Journal
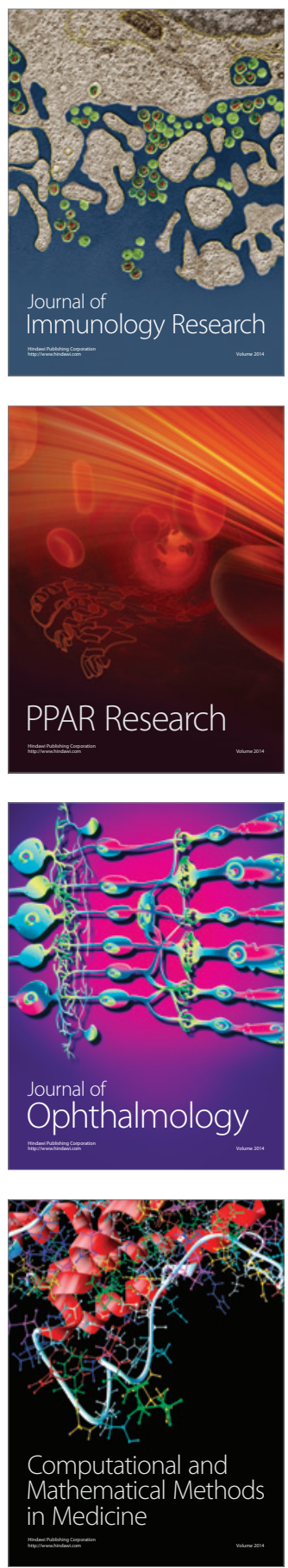

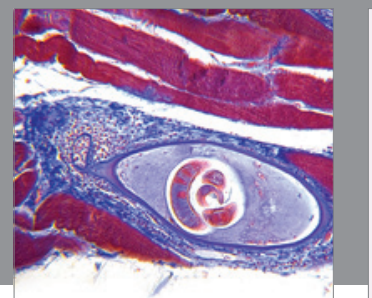

Gastroenterology

Research and Practice
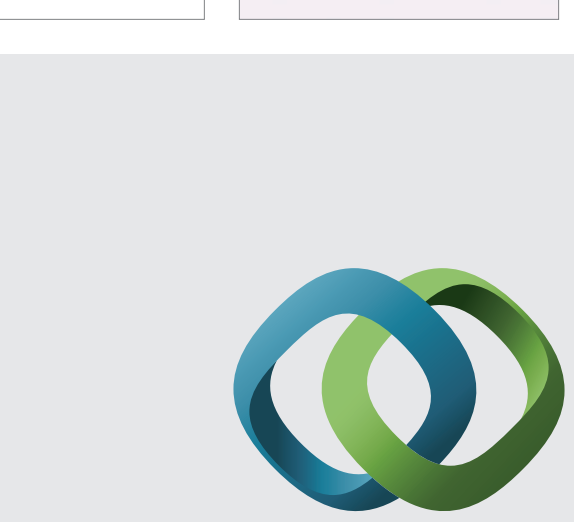

\section{Hindawi}

Submit your manuscripts at

http://www.hindawi.com
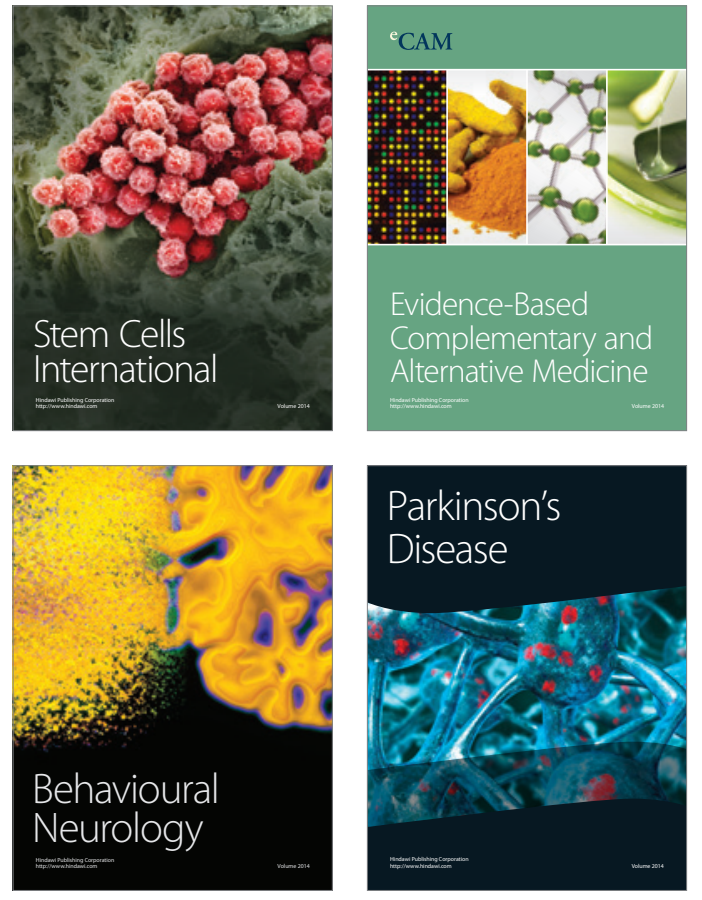
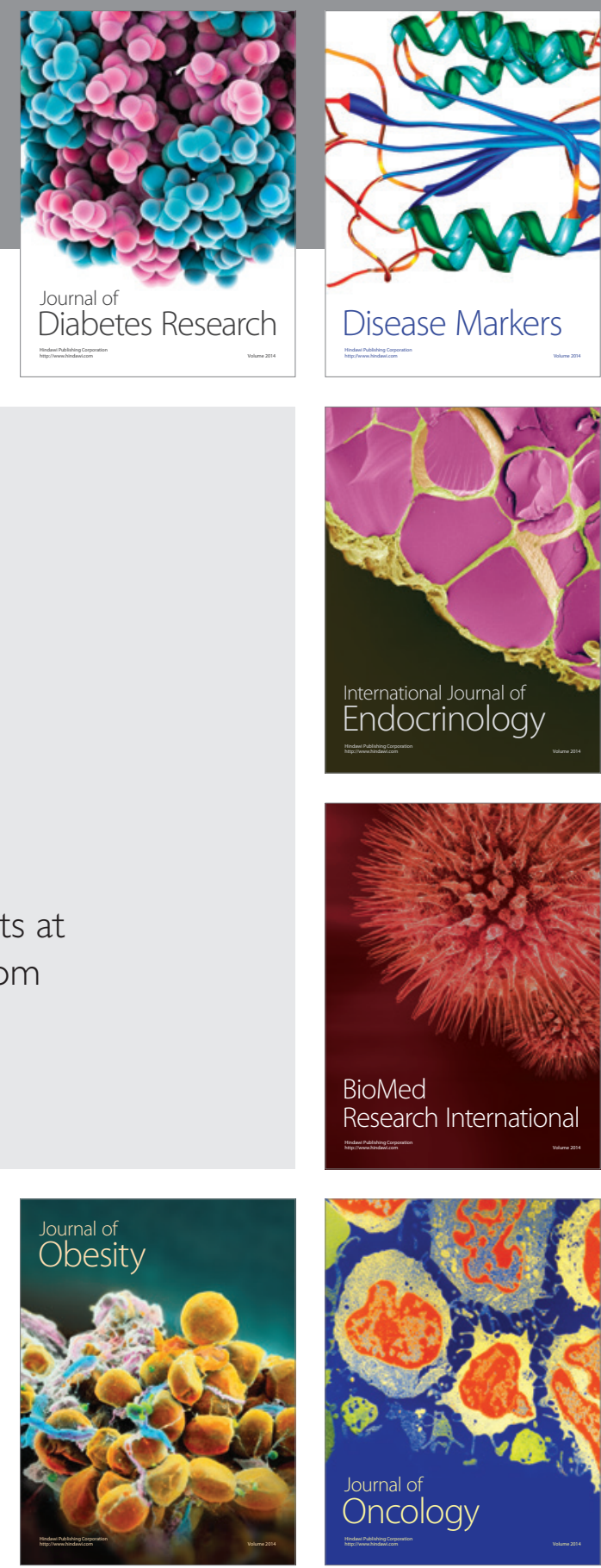

Disease Markers
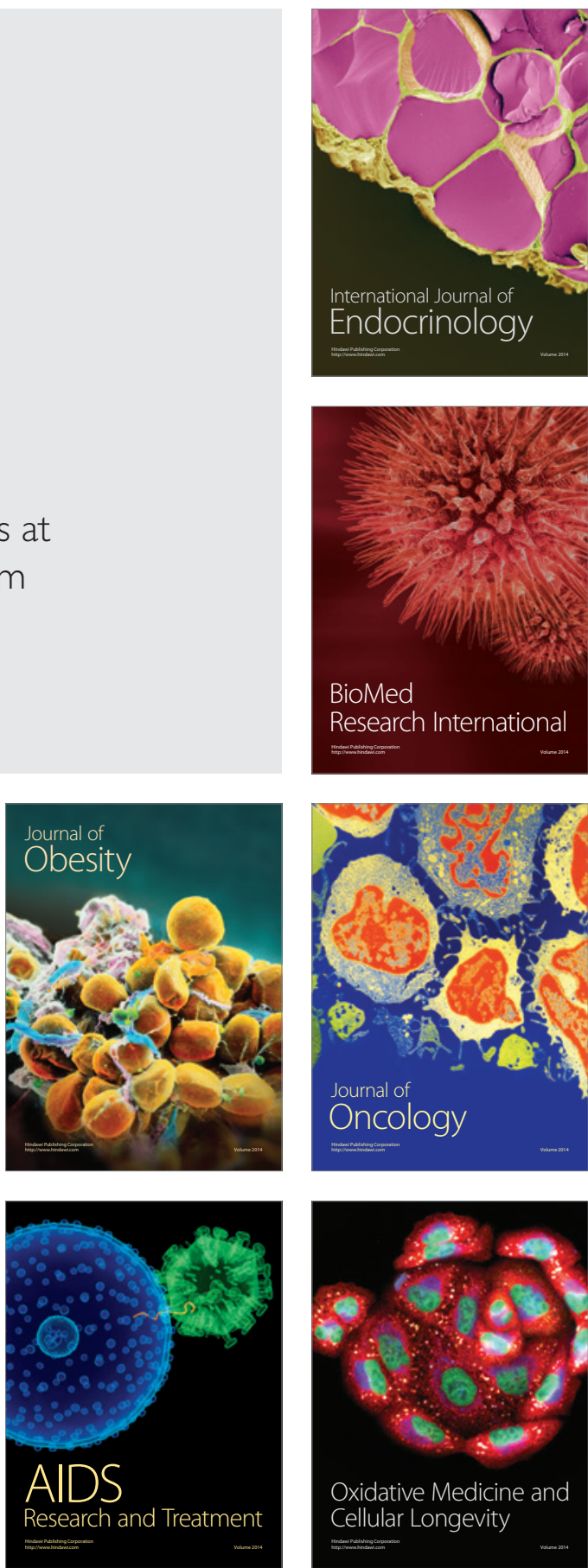